\title{
Attitudes toward Domestic Violence among Korean Immigrants
}

\section{Bonnie Ahn*}

Department of Health and Human Services, Southeastern Louisiana University, Hammond, USA

*Corresponding author: Bonnie Ahn, Department of Health \& Human Services, Southeastern Louisiana University, Hammond, LA 70402,USA, Tel: 985/549-2065; Email: bahn@selu.edu

Received date: December 15, 2013, Accepted date: April 29, 2014, Published date: May 6, 2014

Copyright: @ 2014 Bonnie Ahn. This is an open-access article distributed under the terms of the Creative Commons Attribution License, which permits unrestricted use, distribution, and reproduction in any medium, provided the original author and source are credited.

\begin{abstract}
This study examined various demographic characteristics, the attitudes toward partner abuse, and the relationship between the attitudes toward partner abuse and the incidence of partner abuse among first generation Korean Americans. The study employed a correlational explanatory design using a cross-sectional survey technique utilizing a total of 223 Korean immigrant adults currently residing in Louisiana. A three-part instrument was used for data collection. The use of domestic violence among Korean immigrants was highly prevalent. Korean Americans generally did not approve the use of interpersonal violence against spouses/partners. The relationship between the attitudes toward partner abuse and the incidence of partner abuse as perpetrator was significantly correlated.
\end{abstract}

Keywords: Domestic violence; Partner abuse; Korean immigrants

\section{Introduction}

Despite the increased interest in and publicity on domestic violence, and the substantially increased research on domestic violence during the last few decades, it is only recently that researchers have begun to study diversity and complexity among minority populations in the problem of domestic violence [1]. Particularly, a review of the available literature revealed that very little research has been conducted on partner abuse in Korean immigrant families. Overall, the domestic violence problem in Korean immigrant families has been largely neglected by researchers.

Attitudes toward domestic violence are rooted in Korean traditional values toward the family, marriage and sex-roles. These fundamental orientations reflect more on recent immigrants than people whose families have lived in the West for a longer time, such as third and fourth generation Asian Americans [2]. One major fundamental difference between East and West is the orientation toward the family and the group rather than the individual [2]. Since the family is viewed as more important than the individual, its needs take precedence over the individual's needs. The Korean concept of "loss of face" implies that the entire family loses respect and status in the community when an individual is shamed. This places a severe burden on the individual to keep harmony, and to minimize any conflicts and problems, which could bring guilt and shame to the family.

In order to maintain order and peace in the family, Korean women have developed an ability to absorb insults and injuries without protest and to assume responsibility for others' faults. In many cases, Korean battered women are exemplified as society's image of an ideal woman as submissive, self-blaming, and accepting of whatever the married life brings. Song argues that wife battering in Korean immigrant families is a product of the long history of the Korean tradition that demands endurance and self-blame from a wife while tolerating abusive behavior of a husband [3].

The relationship hierarchy in Korean culture specifies a defined gender role expectation, distinguishing men from women. Members of the family are expected to conform to their specified role in the family. Males are highly valued in Korean culture. Comparatively, females are subjugated and devalued. The results from Song's study showed that a significant proportion of Korean immigrant wives, regardless of their employment status; continue to live by rigidly defined traditional sex roles [3]. It was also observed that while the majority of the wives performed most of the household tasks, many husbands were involved in certain tasks such as paying the bills and making decisions to buy things for the family. The high correlation between wife battering incidence and rigid sex role is in part explained by the combination of the wives' discontent with their husbands' strong demand for an ideal traditional Korean wifehood and the men's unwillingness to concede the absolute male dominant sex role.

The purpose of this study was to examine the attitudes toward domestic violence and various demographic characteristics among Korean immigrants, and also to investigate if the attitudes toward partner abuse and the incidence of domestic violence are related among Korean immigrants. The objectives included: (1) Describe Korean immigrants on selected demographic characteristics including gender, age, length of residence in the United States, occupation, household income, and educational status; (2) Determine the selfreported incidence of domestic violence as perpetrator among Korean immigrants as measured by Conflict Tactics Scale; (3) Determine the attitudes toward partner abuse among Korean immigrants, as measured by the Contextual Justification of Domestic Violence ScaleRevised and (4) Determine the correlation between the incidence of domestic violence, and the attitudes toward domestic violence among Korean immigrants [4,5].

\section{Literature Review}

When Korean families immigrated to the United States, they were likely to undergo stressful experiences in the host society due to behaviors and norms that are quite different from those of home. Not only can this, but also a loss of social status and ties with support systems, lack of individual resources including transportation and appropriate language skills cause numerous stressors. Many Korean 
immigrants were also confronted by unemployment or underemployment and experience racism and discrimination.

There have been a few studies investigating the problem of domestic violence among Korean Americans in the last decades [3,6]. These studies indicate that marital violence is more prevalent among the Korean immigrant population in comparison to other ethnic groups in the United States. According to the records of the Los Angeles County Attorneys' Office, Korean immigrant males comprised the highest percentage of all Asian defendants accused of spouse abuse (Chun, 1990). Also, the quarterly statistics presented by the Korean American Family Service Center consistently indicates that domestic violence is the leading category of the cases serviced by the Center [7-9].

There are old Korean sayings, which reflect traditional perceptions towards women and their expected roles, such as "the real taste of dried fish and women can only be derived from beating them once every three days"; "once you are married, you should be willing to end up as a ghost in your husband's house"; and "be deaf for three years, be mute for another three years, and be blind for another three years, then, you will make your marriage". It perpetuates the notion that a man can beat a woman when she does something wrong, and woman does not have other options than suffering and persevering these inhumane acts.

Suffering and persevering are valued virtues for women in Korean cultures. The ability to persevere and suffer is fundamental to building a strong character. This emphasis on suffering and persevering has been adaptive in Korean culture in that it serves to preserve harmony and order in the family. Women are given support and recognition for enduring hardship and are discouraged from speaking up. Thus, they are taught to accept their suffering rather than change an intolerable situation. The concept of enduring suffering and persevering is also consistent with Buddhism's belief in the acceptance of fate [2]. In Korean philosophy and religion, fate is considered to be positive rather than negative. In Korean philosophy, it is important to accept a situation as fate or destiny intended, and not to challenge it. This concept, therefore, further supports the maintenance of tradition and order, and discourages attempts to change problematic situations such as violence in the family.

Researchers have postulated the relationship between sociodemographic characteristics and domestic violence [10-12]. These reports indicate that there is a correlation between age, income, education, and other sociodemographic characteristics and domestic violence. Some studies identified unemployment, underemployment, or job dissatisfaction as a stress-evoking factor leading to domestic violence [3].

Attitudes toward domestic violence are rooted in the Korean tradition of patriarchy, in which Korean males enjoy power and the right of decision making [3]. Dobash and Dobash also postulated that patriarchal beliefs endorse sanction of employing violence [13]. Patriarchal beliefs are reflected in an exceptionally high rate of violence among Koreans [3]. Permissive attitudes that allow interpersonal violence as an acceptable part of relationships increase the risk of abusive behavior.

\section{Method}

This study employed a correlational explanatory design using a cross-sectional survey technique. Given the sensitive and dangerous nature of partner abuse, there cannot be an experimental component of randomly assigning the condition of partner abuse.

\section{Population and Sample}

In order to establish the frame of the accessible population, the researcher used the Korean Directory of Baton Rouge, published by the Korean Association of Baton Rouge [14]. A total of two hundred and twenty-three Korean immigrant adults (105 males and 118 females) were listed in this directory. After obtaining the university IRB's approval, a sample of 223 first generation Korean American adults were asked to participate in the study.

An introductory letter, an informed consent and a copy of the instrument written in Korean were mailed to all two hundred and twenty-three Korean immigrants with a stamped, self-addressed return envelope. The researcher's name, address, and telephone number were listed in the letter in the event any questions were raised. After ten days, a reminder post card was sent to all participants. Following another ten days, a telephone call was made to all participants who failed to return the completed instrument. Another set of the study instruments were provided to those who indicated a willingness to participate but who were unable to locate their original copies. At least three attempts, at three different times/days were made to contact these participants before a subject was declared as a noncontact and placed with the refusal group.

\section{Instrumentation}

A three-part instrument was utilized for data collection. Part I of the instrument consisted of a measure of the attitudes toward domestic violence. The Contextual Justification Scale-Revised was employed to assess individuals' attitudes sanctioning domestic violence. It is comprised of eleven closed-ended items [5]. A scenario describing a man hitting his wife or partner really hard under nine different situations are presented to respondents. Utilizing a six point Like rttype scale, respondents selected the extent to which they agree or disagree that the violence was justified. The Cronbach's Alpha for this scale in the current study was $a=.97$.

Part II of the instrument consisted of a measure of incidence and nature of domestic violence. The Conflict Tactics Scale (CTS) is comprised of three different subscales: Reasoning, Verbal Aggression, and Physical Violence subscales [4]. In this study the Physical Violence subscale was used to measure physical violence within the last 12 months as perpetrator. The Cronbach's Alpha for this scale was a $=.87$.

Part III of the instrument, the Participant Profile Form is a demographic form developed by the investigator using information derived from the relevant literature. The characteristics included: gender, age, length of residence in the United States, occupation, household income, and educational status.

\section{Findings}

This section presents findings of each objective. The results are organized by the objectives.

\section{Demographic Characteristics of the Sample}

A total of 154 (75.5\%) Korean Americans provided usable data in response to the survey. The demographic data showed that the gender of respondents was split proportionally $(\mathrm{N}=79$ males or $51.3 \%$, and 
Citation: Bonnie Ahn (2014) Attitudes toward Domestic Violence among Korean Immigrants. Arts Social Sci J S: 002. doi:

Page 3 of 5

$\mathrm{N}=75$ females or $48.7 \%)$. The mean age of the respondents was 37.85 years $(\mathrm{SD}=12.19)$, with the range from 18 to 66 years of age. The mean years of residence in the United States was 10.84 years $(\mathrm{SD}=8.32)$. Approximately one half of the respondents ( $\mathrm{n}=84$ or $54.5 \%$ ) indicated the length of their residence in the U.S. as 10 years or less, and the majority of respondents ( $\mathrm{n}=139$ or $90.3 \%)$ had resided in the U.S. 20 years of less. The greatest number of participants was self-employed ( $\mathrm{n}$ $=42$ or $27.3 \%$ ). The next most frequently reported categories were clerical, salesperson $(n=32$ or $20.8 \%)$, student $(n=22$ or $14.3 \%)$, and professional $(\mathrm{n}=19$ or $12.3 \%)$. The mean annual family income was $\$ 44,861.75$ ( $\mathrm{SD}=37,523.93)$. The majority of participants $(\mathrm{n}=75$ or $50.3 \%$ ) had annual family incomes between $\$ 20,000$ and $\$ 39,999$. The largest number of participants had completed a Bachelors degree $(\mathrm{n}=45$ or $29.2 \%)$ (Table 1$)$.

\begin{tabular}{|c|c|c|}
\hline & $\mathrm{n}$ & $\%$ \\
\hline \multicolumn{3}{|l|}{ Age } \\
\hline 25 or less & 26 & 16.9 \\
\hline $26-30$ & 22 & 14.3 \\
\hline $31-35$ & 28 & 18.2 \\
\hline $36-40$ & 18 & 11.6 \\
\hline $41-45$ & 22 & 15.0 \\
\hline $46-50$ & 8 & 5.2 \\
\hline $51-55$ & 9 & 5.8 \\
\hline $56-60$ & 14 & 9.1 \\
\hline 61 or more & 6 & 3.0 \\
\hline \multicolumn{3}{|l|}{ Years in the U.S. } \\
\hline 5 or less & 57 & 37.0 \\
\hline $6-10$ & 27 & 17.5 \\
\hline $11-15$ & 35 & 22.8 \\
\hline $16-20$ & 20 & 13.0 \\
\hline $21-25$ & 4 & 2.6 \\
\hline $26-30$ & 6 & 3.9 \\
\hline $31-35$ & 4 & 2.6 \\
\hline 36 or more & 1 & 0.6 \\
\hline \multicolumn{3}{|l|}{ Occupation } \\
\hline Self-Employed & 42 & 27.3 \\
\hline Clerical, Salesperson & 32 & 20.8 \\
\hline Student & 22 & 14.3 \\
\hline Professional & 19 & 12.3 \\
\hline Skilled Work & 15 & 9.7 \\
\hline Housewife & 12 & 7.8 \\
\hline Manual Work & 6 & 3.9 \\
\hline Unemployed & 4 & 2.6 \\
\hline
\end{tabular}

\begin{tabular}{|c|c|c|}
\hline $\begin{array}{l}\text { Semi-Professional, } \\
\text { manager }\end{array}$ & 2 & 1.3 \\
\hline \multicolumn{3}{|l|}{ Annual Family Income } \\
\hline$<\$ 10,000$ & 1 & 0.7 \\
\hline$\$ 10,000-\$ 19,999$ & 9 & 1.3 \\
\hline$\$ 20,000-\$ 29,999$ & 37 & 24.8 \\
\hline$\$ 30,000-\$ 39,999$ & 38 & 25.5 \\
\hline$\$ 40,000-\$ 49,999$ & 24 & 16.2 \\
\hline$\$ 50,000-\$ 59,999$ & 17 & 11.4 \\
\hline$\$ 60,000-\$ 69,999$ & 8 & 5.3 \\
\hline$\$ 70,000-\$ 79,999$ & 3 & 2.0 \\
\hline$\$ 80,000-\$ 89,999$ & 1 & 0.7 \\
\hline$\$ 90,000-\$ 99,999$ & 3 & 2.0 \\
\hline$\$ 100,000-\$ 199,000$ & 5 & 3.4 \\
\hline$>\$ 200,000 a$ & 3 & 2.0 \\
\hline \multicolumn{3}{|l|}{ Educational Status } \\
\hline Less than High School & 24 & 15.6 \\
\hline $\begin{array}{l}\text { High School Diploma (or } \\
\text { Equivalent) }\end{array}$ & 39 & 25.3 \\
\hline Junior College Degree & 24 & 15.6 \\
\hline Bachelors Degree & 45 & 29.2 \\
\hline Masters Degree & 19 & 12.3 \\
\hline Doctorate & 3 & 1.9 \\
\hline
\end{tabular}

Table 1: Demographic Characteristics of Korean Immigrants.

\section{Incidence and Prevalence of Physical Abuse}

At least once during the last 12 months, $30.2 \% \quad(n=38)$ of respondents used minor physical violence indicating that they threw something at the other person or pushed, grabbed, shoved, or slapped their spouse/partner. No one reported use of a knife or gun on other person, although three respondents $(2.4 \%)$ indicated that they threatened with a knife or gun on other person at least once during the last 12 months. The rate for severe physical violence was $15.1 \%$ during the last 12 months. Thirteen respondents (10.3\%) reported that they beat up the other person at least once, 19 respondents (15.1\%) reported that they kicked, bit, or hit with a fist at least once, and 19 respondents $(15.1 \%)$ reported that they hit or tried to hit the other person with some objects at least once during the last 12 months. The rate for overall physical violence as perpetrator was $30.2 \%$ (Table 2).

\begin{tabular}{|l|l|l|l|l|l|l|}
\hline $\begin{array}{l}\text { Physical } \\
\text { Violence }\end{array}$ & Yes & & No & & & Total \\
\hline & $\mathrm{n}$ & $\%^{\mathrm{a}}$ & $\mathrm{n}$ & $\%^{\mathrm{a}}$ & $\mathrm{n}$ & $\%^{\mathrm{a}}$ \\
\hline $\begin{array}{l}\text { Minor } \\
\text { Physical } \\
\text { Violence }\end{array}$ & 38 & 30.20 & 88 & 69.80 & 126 & 100 \\
\hline
\end{tabular}


Page 4 of 5

\begin{tabular}{|l|l|l|l|l|l|l|}
\hline $\begin{array}{l}\text { Threw } \\
\text { something } \\
\text { at the } \\
\text { other } \\
\text { person }\end{array}$ & 38 & 30.20 & 88 & 69.80 & 126 & 100 \\
\hline $\begin{array}{l}\text { Pushed, } \\
\text { grabbed, } \\
\text { or shoved } \\
\text { the other } \\
\text { person }\end{array}$ & 30 & 23.80 & 96 & 76.20 & 126 & 100 \\
\hline $\begin{array}{l}\text { Slapped } \\
\text { the other } \\
\text { person }\end{array}$ & 26 & 20.60 & 100 & 79.40 & 126 & 100 \\
\hline $\begin{array}{l}\text { Severe } \\
\text { Physical } \\
\text { Violence }\end{array}$ & 19 & 15.10 & 107 & 84.90 & 126 & 100 \\
\hline $\begin{array}{l}\text { Kicked, bit, } \\
\text { or hit with } \\
\text { fist }\end{array}$ & 19 & 15.10 & 107 & 84.90 & 126 & 100 \\
\hline $\begin{array}{l}\text { Hit or tried } \\
\text { to hit the } \\
\text { other } \\
\text { person } \\
\text { with same } \\
\text { objects }\end{array}$ & 19 & 15.10 & 107 & 84.90 & 126 & 100 \\
\hline $\begin{array}{l}\text { Beat up } \\
\text { the other } \\
\text { person }\end{array}$ & 13 & 10.30 & 113 & 89.70 & 126 & 100 \\
\hline $\begin{array}{l}\text { Threatene } \\
\text { d with a } \\
\text { knife or } \\
\text { gun on the } \\
\text { person }\end{array}$ & 3 & 2.40 & 123 & 97.60 & 126 & 100 \\
\hline $\begin{array}{l}\text { Used a } \\
\text { knife or } \\
\text { gun on } \\
\text { other } \\
\text { person }\end{array}$ & 0 & 0.00 & 126 & 100.00 & 126 & 100 \\
\hline $\begin{array}{l}\text { Overall } \\
\text { Physical } \\
\text { Violence }\end{array}$ & 38 & 30.20 & 88 & 69.80 & 126 & 100 \\
\hline
\end{tabular}

Table 2: Korean Immigrants' Use of Physical Violence during the Past 12 Months. apercentage based on the total number of 126 respondents. 28 respondents did not respond due to their marital status of not living with someone during the past 12 months.

\section{Attitudes toward Domestic Violence}

In the Attitudes toward the Contextual Justification of Domestic Violence Scale, respondents were asked to indicate their level of agreement/disagreement regarding whether it is appropriate to "hit" in selected situations. Of the 11 items included in the scale, one had a mean rating in the "Agree" response category. This item was "He acted in self-defense" ( $M=1.75, \mathrm{SD}=1.36)$. The items with which respondents disagreed most included: "When she does not spend enough time at home" $(\mathrm{M}=4.97, \mathrm{SD}=1.34)$, "When he was in a bad mood" $(\mathrm{M}=4.88$, $\mathrm{SD}=1.50)$, "When she was trying to hurt their child" $(\mathrm{M}=4.73$, $\mathrm{SD}=1.58)$, "When she was unwilling to have $\operatorname{sex}$ " $(\mathrm{M}=4.61, \mathrm{SD}=1.65)$, and "When he caught her having an affair" $(M=4.56, \mathrm{SD}=1.50)$. These items were in the "Disagree" response category. An overall mean for the Contextual Justification Scale-Revised was $4.20(\mathrm{SD}=1.37)$, which was classified as "Disagree Somewhat" response category by the interpretive scale established by the researcher (Table 3 ).

\begin{tabular}{|l|l|l|l|}
\hline Item & $\mathrm{M}^{\mathrm{a}}$ & SD & $\begin{array}{l}\text { Response }^{\mathrm{b}} \\
\text { Category }^{\mathrm{N}}\end{array}$ \\
\hline $\begin{array}{l}\text { He acted in self- } \\
\text { defense }\end{array}$ & 1.75 & 1.36 & $\mathrm{~A}$ \\
\hline $\begin{array}{l}\text { He caught her } \\
\text { having an affair }\end{array}$ & 3.66 & 1.77 & DS \\
\hline $\begin{array}{l}\text { She was } \\
\text { screaming } \\
\text { hysterically }\end{array}$ & 4.05 & 1.47 & DS \\
\hline $\begin{array}{l}\text { He found her } \\
\text { flirting with } \\
\text { someone else }\end{array}$ & 4.27 & 1.70 & DS \\
\hline $\begin{array}{l}\text { She was always } \\
\text { nagging }\end{array}$ & 4.36 & 1.55 & DS \\
\hline $\begin{array}{l}\text { She did not obey } \\
\text { him }\end{array}$ & 4.38 & 1.70 & DS \\
\hline $\begin{array}{l}\text { He found her } \\
\text { drunk }\end{array}$ & 4.56 & 1.50 & D \\
\hline $\begin{array}{l}\text { She was unwilling } \\
\text { to have sex }\end{array}$ & 4.61 & 1.65 & D \\
\hline $\begin{array}{l}\text { She was trying to } \\
\text { hurt their child }\end{array}$ & 4.73 & 1.58 & D \\
\hline $\begin{array}{l}\text { He was in a bad } \\
\text { mood }\end{array}$ & 4.88 & 1.50 & D \\
\hline $\begin{array}{l}\text { She does not } \\
\text { spend } \\
\text { time at home }\end{array}$ & 4.97 & 1.34 & \\
\hline
\end{tabular}

Table 3: Korean Immigrants' Attitudes toward the Contextual

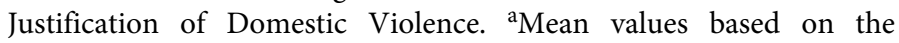
response scale $1=$ strongly agree, $2=$ agree, $3=$ agree somewhat, $4=$ disagree somewhat, $5=$ disagree, $6=$ strongly disagree. ${ }^{b}$ Response categories based on the following scale established by the researcher: SA-Strongly Agree $=<1.51$. A-Agree $=1.51$ to 2.50, AS-Agree Somewhat $=2.51$ to 3.50 , DS-Disagree Somewhat $=3.51$ to 4.50 , DDisagree $=4.51$ to 5.50 , and SD-Strongly Disagree $=>5.50$.

\section{Relationship between the Attitudes toward Domestic Violence and the Incidence}

When the Contextual Justification score was correlated with the incidence of partner abuse scale in perpetrator dimension, the calculated correlation was found to be significant. The correlation was $\mathrm{r}=.65$ ( $\mathrm{p}<.001)$. This relationship as characterized by Davis' descriptors was a substantial association (Davis, 1971). The nature of this relationship was such that individuals who accepted a wider range of Contextual Justification (higher scores on the Contextual Justification Scale-Revised) tended to report higher scores on the incidence of Physical Violence in partner abuse.

\section{Conclusions, Limitations, and Recommendations}

The use of physical violence among Korean immigrants is highly prevalent. The prevalence rate in this study was higher in comparison to the results of two National Family Violence Surveys conducted to 
estimate the occurrences of marital violence [15]. Although no use of a gun or a knife was reported, approximately thirty percent of the respondents in this study used minor violence including pushing or slapping their spouse/partner.

Korean immigrants generally do not approve the use of interpersonal violence against spouses/partners. Clarke et al. also demonstrated in their studies that dating violence was not generally justified under various circumstances except for some reported ambivalence when used in self-defense [16]. These findings reflect changes in the public's attitudes toward interpersonal violence. According to the estimate of Dibble and Straus in 1980, 28\% of Americans believed that hitting a spouse was sometimes necessary, normal, or good and that one third had actually slapped a spouse. Due to much gained publicity through a battered women's movement in the latter part of the twentieth century, and the increase in media campaigns in their prevention efforts, public awareness of the problems stemming from domestic violence increased and this increased awareness is reflected in the public's perception regarding the use of aggression against spouses.

Although this study has provided an in-depth analysis of domestic violence among Korean immigrants, there are several limitations. Because our sample is limited to the Korean immigrants in the South and the sample was a nonprobability sample, this study cannot be generalized to all Korean immigrant populations, and future researchers are encouraged to expand the participant pool to include a wider probability sample. The manner in which respondents define domestic violence and the incidence rate may have been influenced by some socio-economic factors such as the age of the respondents, education, income, and the employment status. Future researches are recommended to study the relation between socio-economic factors and the definition of domestic violence and the incidence rate. Due to this study being a cross-sectional design, attitudes may change over time and therefore may require a longitudinal design to measure whether or not attitudes change across the respondents' length of residence in the U.S. Additionally; an investigator might choose to examine a problem qualitatively rather than quantitatively due to the sensitive nature of the topic of domestic violence. The quantitative findings of the current study may also need more explanations for better understanding of the problem.

The researcher recommends community education and concerted public awareness campaigns given the high prevalence rate of domestic violence. Educational efforts should include helping individuals to identify the potential abuse early in the relationship and to develop problem-solving and conflict resolution skills, ultimately preventing occurrences of violence between couples.

This researcher also recommends that in the Korean American community, public campaigns should be initiated in the Korean language that disseminate information about the effects of domestic violence, so that public attitudes toward family violence will continue to change. Major social service agencies in the Korean community should apply for funding or grants for this purpose.

For policy implications, the researcher recommends preparing all educational campaign materials in the Korean language and hiring

This article was originally published in a special issue, entitled: "Violence against Immigrant Women: A Global Perspective throughout the LifeCycle", Edited by Nawal H Ammar, University of Ontario Institute of Technology, Canada
Korean speaking staff to deliver services effectively. Language problems and social isolation are frequently associated with episodes of battering [3]. Language problems and social isolation are well known as a major obstacle, causing frustration for Koreans in the process of making a new life in the United States. For the locations of service delivery, meetings should be held and agencies must be located in communities where a high concentration of Korean immigrants resides. Many Korean immigrants, particularly those who arrived more recently do not have transportation means and are reluctant to travel distances.

\section{References}

1. West CM (1998) Lifting thepolitical gag order: Breaking the silence around partner violence in ethnic minority families, In: Partner violence: A comprehensive review of 20 years of research.Jasinski JL, Williams ML(eds.)Sage Publications, USA: 184-209.

2. Ho CK (1990) An analysis of domestic violence in Asian American communities: A multicultural approach to counseling. In: Diversity and complexity in feminist therapy. LS Brown, Root M (Eds.) New York: Harrington Park: 129-150.

3. Song Y (1996) Battered women in Korean immigrant families: The silent Scream. Garland Publishing Inc, New York, USA.

4. Straus M A (1979) Measuringintrafamily conflict and violence: The Conflict Tactics (CT) Scales. Journal of Marriage \& the Family 41: 75-88.

5. Yick AG (1997) Chinese-Americans' perceptions of and experiences with domestic violence and factors related to their psychological well-being. University of California, Los Angeles.

6. Ahn B (2002) The Perceptions of and Attitudes toward partner abuse among first generation Korean-Americans: their relationships to the incidence of partner abuse. Doctoral dissertation, Louisiana State University.

7. Korean American Family Service Center (2010) The quarterly statistical report. Los Angeles, California, USA.

8. Korean American Family Service Center (2011) The quarterly statistical report. Los Angeles, California, USA.

9. Korean American Family Service Center (2012) The quarterly statistical report. Los Angeles, California, USA.

10. Bachman R, Saltzman LE (1995) Violence against women: Estimates from the redesigned survey (Bureau of Justice Statistics special report). US Department of Justice.

11. Hoffman KL, Demo DH, Edwards JN (1994) Physical wife abuse in a non-Western society: An integrated theoretical approach. Journal of Marriage and the Family 56: 131-146.

12. Hutchison IW, Hirschel JD, Pesackis CE (1994) Family violence and police utilization. Violence and Vict9: 299-313.

13. Dobash RE, Dobash RP (1978) Wives: The "appropriate" victims of marital violence. Victimology 2: 426-442.

14. Korean Immigrants Association of Baton Rouge (2010) Korean Immigrants Directory of Baton Rouge.

15. Straus MA (1990) The National Family Violence Surveys. In: Physical violence in American families: Risk factors and adaptations to violence in 8,145 families. Straus MA, Gelles RJ (eds.) Transaction Books, Brunswick, NJ: 3-16.

16. Clark ML, Beckett J, Wells M, DungeeAD (1994) Courtship violence among African American college students. Journal of Black Psychology 20: 264-281. 